\title{
Effect of low-sugar and High-dietary Fiber Noodles on Glycemic Response in Healthy Humans: A Cross-over Trial
}

\section{Kazunari Kadokura \\ Kibun Foods Inc. \\ Tsuyoshi Tomita \\ Kibun Foods Inc. \\ Sachiyo Hata \\ Kibun Foods Inc. \\ Kazuhiko Kamata \\ Kibun Foods Inc.}

Kohei Suruga ( $\nabla$ kouhei_suruga@kibun.co.jp )

Kibun Foods Inc. https://orcid.org/0000-0001-9430-9620

\section{Research}

Keywords: Low-sugar high-dietary fiber noodles diet, Blood glucose, Insulin

Posted Date: November 20th, 2020

DOI: https://doi.org/10.21203/rs.3.rs-111425/v1

License: (c) (i) This work is licensed under a Creative Commons Attribution 4.0 International License. Read Full License 


\section{Abstract}

Background: Low-carbohydrate diets are popular nutritional therapeutics based on recommendations of the American Diabetes Association (2013). In previous reports, we suggested a new diet-intake restriction method using low-sugar, high-dietary fiber noodles containing okara and konjac and reported their effect on blood glucose levels in healthy animals and animal models of type 2 diabetes. This study aimed to compare the effect of low-sugar, high-dietary fiber noodles with that of normal wheat noodles on glycemic response in healthy adult men.

Methods: The study was a randomized, cross-over design to investigate the effects of normal wheat noodles versus low-sugar, high-dietary fiber noodles on glucose and insulin responses at $120 \mathrm{~min}$. Plasma glucose and insulin levels were measured at 0, 15, 30, 45, 60, and 120 min after intake of normal wheat noodles or low-sugar, high-dietary fiber noodles.

Results: No abnormalities and side effects were observed in the low-sugar, high-dietary fiber noodles group. Additionally, in men who consumed low-sugar, high-dietary fiber noodles, the increase in postprandial blood glucose levels and insulin levels was significantly suppressed compared with that in men who consumed normal wheat noodles. Conclusions: To the best of our knowledge, this is the first report on the effectiveness of low-sugar, high-dietary fiber noodles on postprandial blood glucose levels in healthy humans; our findings also suggest that such type of noodles might be beneficial for patients with diabetes or celiac disease who consume noodles.

Trial registration: UMIN000023986

\section{Background}

The prevalence of type 2 diabetes mellitus is rising globally, and is related to health consequences and healthcare costs [1]. The American Diabetes Association and the British Diabetic Association reported that low-carbohydrate diets (LCDs) may be effectively used as a medical nutritional therapy to manage blood glucose and lipid levels, and that LCDs are effective at lowering blood glucose and hemoglobin A1c (HbA1c) levels [2-4].

Grains such as rice and noodles prepared using rice and wheat are the primary carbohydrate sources for almost all Asian populations [5], and have become a popular food product worldwide [6]. In particular, a vast number of noodles products are made from refined wheat, and the popularity of Asian noodles is increasing around the world [6]. However, high consumption of noodles leads to a higher risk of type 2 diabetes, similar to that observed for high rice consumption [7]. Moreover, oxidative stress and insulin resistance caused by regular remarkable postprandial glycaemia have been identified as important factors contributing to the onset of type 2 diabetes [8]. Therefore, dietary control which shows the suppression of increase in postprandial blood glucose levels is an important strategy against progression of type 2 diabetes [9]. 
From these backgrounds, we have developed low-sugar, high-dietary fiber (LS-HDF) noodles containing a by-product obtained following the processing of soybeans, Glycine max (commonly called "okara") and Amorphophallus konjac (commonly called "konjac") for those who consume noodles regularly. In a previous study, we investigated the effects of LS-HDF noodles intake on blood glucose levels in mouse and rat models for type 2 diabetes [10-12]. However, there are no experimental data on the effects of LSHDF noodles intake on glycemic response in humans.

In this preliminary study, we have demonstrated the effects of LS-HDF noodles on glycemic response in healthy humans as a cross-over trial for the first time.

\section{Materials And Methods}

\section{Materials}

Commercial LS-HDF noodles (Healthy Noodles ${ }^{\mathrm{TM}}$ from Kibun Foods Inc., Japan) were used (Fig. 1). In brief, okara was mixed with konjac and other ingredients and then boiled. Commercial wheat noodles were used as control noodles. Energy (kcal), proteins ( $\mathrm{g})$, fats $(\mathrm{g})$, and carbohydrates $(\mathrm{g})$ of control noodles $(180 \mathrm{~g})$ in this study were $209.6,5.5,0.7$, and 45.3 , respectively. By contrast, energy (kcal), proteins $(\mathrm{g})$, fats $(\mathrm{g})$ and carbohydrates $(\mathrm{g})$ of LS-HDF noodles $(180 \mathrm{~g})$ were $35.0,2.4,1.4$, and 11.3 (sugar: 0.0, dietary fiber: 11.3), respectively.

\section{Study design}

Healthy adult men, aged 22 to 35 years, with a body mass index of 18.1 to $23.9 \mathrm{~kg} / \mathrm{m}^{2}$, were recruited from the capital area, including Tokyo, Japan (Table 1). The exclusion criteria were (I) any type of physical and mental chronic diseases including type 1 or type 2 diabetes; (II) positive for syphilis, HIV virus, hepatitis B virus, and hepatitis $C$ virus; (III) regular use of supplements/medications that might interfere with the levels of blood glucose and insulin; (IV) allergy to wheat, soybean, and others; and (V) unwillingness to follow the study protocol. The experiments were performed at Kitasato University, Kitasato Institute Hospital. The experimental protocol was approved by the Human Experiment Ethics Committee of the laboratory, and this clinical trial was registered with the UMIN Clinical Trial Registry (no. UMIN000023986). All participants provided written informed consent. Of the 12 eligible men, 8 were enrolled in this study. 
Table 1

Characteristics of healthy adult men $(n=8)$.

\begin{tabular}{|lll|}
\hline Characteristic & Mean \pm SE & Values (range) \\
\hline Age $(\mathrm{yrs})$ & $28.13 \pm 1.71$ & $22-35$ \\
\hline Weight $(\mathrm{kg})$ & $61.54 \pm 2.00$ & $52.50-70.20$ \\
\hline Height $(\mathrm{cm})$ & $172.23 \pm 1.35$ & $164.30-177.10$ \\
\hline $\mathrm{BMl}\left(\mathrm{kg} / \mathrm{m}^{2}\right)$ & $20.74 \pm 0.63$ & $18.09-23.89$ \\
\hline
\end{tabular}

The study was a randomized, cross-over design to investigate the effects of normal wheat noodles versus LS-HDF noodles on glucose and insulin responses at $120 \mathrm{~min}$ (Table 2). Plasma glucose and insulin levels were measured at $0,15,30,45,60$, and 120 min after intake of normal wheat noodles $(180 \mathrm{~g})$ or LSHDF noodles (180 g). The incremental area under the curve (iAUC) for blood glucose and insulin was assessed between 0-120 min postprandially for all the participants. 
Table 2

Schematic of study protocol.

\begin{tabular}{|c|c|c|c|}
\hline Day & Time & Group I & Group II \\
\hline \multirow[t]{2}{*}{ Day 0} & 03:00 pm & Blood sampling & \\
\hline & $06: 30 \mathrm{pm}$ & Standardized dinne & \\
\hline \multirow[t]{9}{*}{ Day 1} & 08:00 am & Blood sampling & \\
\hline & 09:00 am & LS-HDF noodles & Normal noodles \\
\hline & 09:15 am & Blood sampling & \\
\hline & 09:30 am & Blood sampling & \\
\hline & 09:45 am & Blood sampling & \\
\hline & $10: 00 \mathrm{am}$ & Blood sampling & \\
\hline & $11: 00 \mathrm{am}$ & Blood sampling & \\
\hline & $12: 00 \mathrm{pm}$ & Standardized lunch & \\
\hline & $06: 30 \mathrm{pm}$ & Standardized dinne & \\
\hline \multirow[t]{7}{*}{ Day 2} & 08:00 am & Blood sampling & \\
\hline & 09:00 am & Normal noodles & LS-HDF noodles \\
\hline & 09:15 am & Blood sampling & \\
\hline & 09:30 am & Blood sampling & \\
\hline & 09:45 am & Blood sampling & \\
\hline & $10: 00 \mathrm{am}$ & Blood sampling & \\
\hline & $11: 00 \mathrm{am}$ & Blood sampling & \\
\hline
\end{tabular}

\section{Statistical analysis}

Results are expressed as mean \pm standard error (SE). Statistical significance was determined using a paired $t$-test. A $p$-value of less than 0.05 was considered statistically significant.

\section{Results}

All the participants (8 subjects) who were enrolled in this study completed the study. No abnormalities or side effects were observed in either control noodles or LS-HDF noodles groups. 
The results of change in plasma glucose level are shown in Fig. 2. The postprandial blood glucose levels of the control noodles group increased with time and showed a marked rise at $30 \mathrm{~min}$ after administration. However, the blood glucose levels of the LS-HDF noodles group remained stable for 120 min (Fig. 2-A). The LS-HDF noodles group showed an approximately $98 \%$ reduction in glucose iAUC values compared to the control noodles group (Fig. 2-B).

The results of change in insulin level are shown in Fig. 3. In the group that consumed LS-HDF noodles, the increase in insulin level was significantly suppressed at $120 \mathrm{~min}$ after administration than in the control noodles group (Fig. 3-A). The LS-HDF noodles group exhibited an approximately $99 \%$ reduction in the insulin iAUC values compared to the control noodles group (Fig. 3-B).

\section{Discussion}

Type 2 diabetes mellitus is a chronic metabolic disorder. The morbidity of the world population attributable to diabetes is expected to increase from 415 million in 2015 to 642 million by 2040 [13]. The number of people with diabetes is increasing due to population growth, aging, urbanization, obesity, and physical inactivity [1], and refined carbohydrates, including rice and noodles have been implicated in the deterioration of glucose metabolism [14]. However, rice and noodles are major staple foods of Asian people such as the Chinese, Korean, and Japanese. Therefore, we have developed LS-HDF noodles containing okara and konjac for those who consume noodles regularly. In this study, we demonstrated the effect of LS-HDF noodles on glycemic response in healthy humans as a cross-over trial for the first time.

In a previous study, we investigated the effect of LS-HDF noodles intake on blood glucose levels in healthy ICR mice compared with that of commercial wheat noodles intake and reported that the increase in postprandial blood glucose levels was significantly suppressed after consumption of LS-HDF noodles [10]. In this study, postprandial blood glucose levels of the LS-HDF noodles group remained stable for 120 min after consumption of LS-HDF noodles. This result was almost similar to that of our previous data on mice; however, the difference in postprandial blood glucose levels between healthy humans who consumed wheat noodles and LS-HDF noodles was increased compared with that of healthy mice. The postprandial blood insulin levels of the LS-HDF noodles group remained stable for 120 min after intake of LS-HDF noodles. Accili et al. reported that not only hypoinsulinemia, but also hyperinsulinemia was harmful for body functions [15]. In particular, high levels of insulin levels in otherwise metabolically healthy persons are assumed to pose a risk factor towards the development of obesity $[16,17]$. To prevent obesity in healthy individuals, it is important to suppress the increase in insulin levels. Therefore, we thought that LS-HDF noodles might be effective to prevent obesity. In addition, it is crucial to prevent metabolic syndrome diseases such as hyperglycemia and hyperlipidemia [18]. To reduce the number of individuals suffering from such diseases, it is necessary to develop processed foods that do not stimulate an increase in postprandial blood glucose levels and secretion of insulin [19]. Taking these reports into account, it can be suggested that LCDs such as LS-HDF noodles might be effective in protecting against metabolic syndrome diseases. 
In the present study, we investigated the effect of LS-HDF noodles on glycemic response in healthy humans using a single meal test. In a previous study, we had demonstrated the effect of LS-HDF noodles on blood glucose levels in Spontaneously Diabetic Torii fatty rats, a model for obese type 2 diabetes, using a one-month test ( 28 days administration) and reported that the levels of blood glucose, HbA1c, and glycated albumin levels of the LS-HDF noodles group were significantly lower than those of control group [12]. In our study, after administration of LS-HDF noodles for 28 days, an oral glucose tolerance test (OGTT) indicated that blood glucose levels of the LS-HDF noodles group were significantly lower than those of control group. From this result, we could predict that intake of LS-HDF noodles might be effective for preventing type 2 diabetes in humans. There are benefits and risks of an LCD in type 2 diabetes patients; LCD increases mineral deficiency and hypovitaminosis and reduces dietary fiber intake $[20,21]$. The dietary fiber levels were $11.3 \mathrm{~g}$ in the LS-HDF noodles used in this study $(180 \mathrm{~g})$. This indicates that LS-HDF noodles can replenish dietary fiber in LCDs, and LS-HDF noodles showed antioxidant activity in vitro [12]. Soy residues "okara" which contained a by-product obtained following the processing of soybeans is one of main ingredients in LS-HDF noodles. Okara is only soy residue, even though, it is rich in nutrients. In generally known, okara dry matter contains the insoluble fiber [22], protein [23], lipid [24] and isoflavones [25]. Especially, approximately 40-60\% insoluble fiber (cellulose and hemicellulose) is contained in dried okara. Moreover, Vital et al. reported that phenolic compounds and flavonoids which showed antioxidant activities was contained in okara [26]. Furthermore, in our previous reports, we investigated that okara and fermented okara with Rhizopus oligosporus showed the reactive oxygen scavenging activity [27-28]. Konjac is one of main ingredients in LS-HDF noodles as well as okara. Konjac contained the konjac glucomannan, is water soluble polysaccharide [29]. Zhao et al. carried out the in vivo antioxidant and anti-inflammatory effects of konjac glucomannan in type 2 diabetic rats [30]. Therefore, we expect that the LS-HDF noodles which have the antioxidant activities might be effective for protecting against type 2 diabetes mellitus.

\section{Conclusions}

In conclusion, globally, many people as well as patients with type 2 diabetes consume seasoned staple foods containing rice, bread, and noodles that are rich in carbohydrates; consequently, it may be difficult to follow an LCD in daily life for long periods. There are numerous methods for the management of type 2 diabetes, and one of the effective methods is dietary carbohydrate restriction such as following an LCD. Although an LCD has both benefits and risks, it is important to individualize the diet consumed. In this preliminary study, we have described the effects of LS-HDF noodles in healthy humans using a single meal test and presented new information on simple methods for the management of diabetes.

\section{Abbreviations}

LCDs: low-carbohydrate diets

HbA1c: hemoglobin A1c 
LS-HDF: low-sugar, high-dietary fiber

iAUC: incremental area under the curve

SE: standard error

OGTT: oral glucose tolerance test

\section{Declarations}

\section{Ethics approval and consent to participate}

The experiments were performed at Kitasato University, Kitasato Institute Hospital. The experimental protocol was approved by the Human Experiment Ethics Committee of the laboratory, and this clinical trial was registered with the UMIN Clinical Trial Registry (no. UMIN000023986). All participants provided written informed consent.

\section{Consent for publication}

Not applicable.

\section{Availability of data and materials}

All data generated or analyzed during this study are included in this published article.

\section{Competing interests}

The authors declare that there are no conflicts of interest. The authors have not received funding or benefits from industry or elsewhere to conduct this study.

\section{Funding}

Without funding.

\section{Author Contributions}

Experimental design: Kazunari Kadokura, Kohei Suruga.

Preparation of LS-HDF noodles: Kazunari Kadokura, Tsuyoshi Tomita, Sachiyo Hata, Kazuhiko Kamata, Kohei Suruga. 


\section{Acknowledgement}

We are grateful to Masahito Hoashi, Chairperson and C.E.O. of Kibun Foods Inc., for supporting this study.

\section{References}

1. Wild S, Roglic G, Green A, Sicree R, King H. Global prevalence of diabetes: astimates for the year 2000 and projections for 2030. Diabet Care. 2004;27(5):1047-53.

2. Dyson PA, Kelly T, Deakin T, Duncan A, Frost G, Harrison Z, et al. Diabetes UK evidence-based nutrition guidelines for the prevention and management of diabetes. Diabet Med. 2011;28(11):12828.

3. Wheeler ML, Dunbar SA, Jaacks LM, Karmally W, Mayer-Davis EJ, Wylie-Rosett EJ et al. Macronutrients, food groups, and eating patterns in the management of diabetes: a systematic review of the literature, 2010. Diabet Care. 2012;35(2):434-45.

4. Feinman RD, Pogozelski WK, Astrup A, Bernstein RK, Fine EJ, Frassetto L, et al. Dietary carbohydrate restriction as the first approach in diabetes management: critical review and evidence base. 2015;31(1):1-13.

5. Ahn Y, Park SJ, Kwack HK, Kim MK, Ko KP, Kim SS. Rice-eating pattern and the risk of metabolic syndrome especially waist circumference in Korean Genome and Epidemiology Study (KoGES). BMC Public Health. 2013;13:61.

6. Niu M, Hou GG. Whole wheat noodles: Processing, quality improvement, and nutritional and health benefits. Cereal Chem. 2019;96(1):23-33.

7. Zuñiga YLM, Rebello SA, Oi PL, Zheng H, Lee J, Tai Shyong, et al. Rice and noodle consumption is associated with insulin resistance and hyperglycaemia in an Asian population. $\mathrm{Br} \mathrm{J}$ Nutr. 2014;111:1118-28.

8. Blaak EE, Antoine JM, Benton D, Björck I, Bozzetto L, Brouns F, et al. Inpact of postprandial glycaemia on health and prevention of disease. Obes Rev. 2012;13:923-84.

9. Ley SH, Hamdy O, Mohan V, Hu FB. Prevention and management of type 2 diabetes: Dietary compounds and nutritional strategies. Lancet. 2014;383(9933):1999-2007.

10. Suruga K, Kadokura K, Miyata A, Tomita T, Sekino Y, Terada K, et al. Effect of low-available carbohydrate diet with high dietary fiber using okara and konjac on blood glucose levels in mice [abstract]. Diabetes 2018;67 Suppl 1:2253.

11. Suruga K, Tomita T, Kobayashi M, Mitsui T, Kadokura K. Effect of low-available carbohydrate diet with high dietary fiber using okara and konjac on blood glucose levels in Spontaneous diabetic Torii fatty rats [abstract]. Diabetes 2020;69 Suppl 1:2167. 
12. Suruga K, Tomita T, Kadokura K. Effect of low-sugar and high-dietary fiber noodles diet on blood glucose levels in Spontaneously diabetic Torii fatty rats. J Nutr Food Sci. 2020;10(4).

13. International Diabetes Federation: IDF Diabetes Atlas 7th edition 2015. http://www.diabetesatlas.org/. Accessed 10 Nov 2020.

14. Nanri A, Mizoue T, Noda $M$, Takahashi $Y$, Kato $M$, Inoue $M$, et al. Rice intake and type 2 diabetes in Japanese men and women: the Japan public health center-based prospective study. Am J Clin Nutr. 2010;92:1468-77.

15. Accili D, Drago J, Lee EJ, Johnson MD, Cool MH, Salvatore P, et al. Early neonatal death in mice homozygous for a null allele of the insulin receptor gene. Nat Genet. 1996;12(1):106-9.

16. Appel KE, Farr CB, Marshall HK. Insulin in undernutrition in the psychoses. Arch NeurPsych. 1929;21(1):149-64.

17. Kolb H, Kempf K, Röhling M, Martin S. Insulin: too much of a good thing is bad. BMC Med. 2020;18:

18. Nathan DM, Buse JB, Davidson MB, Heine RJ, Holman RR, Sherwin R, et al. Management of hyperglycemia in type 2 diabetes: a consensus algorithm for the initiation and adjustment of therapy. Diabet Care. 2006;29(8):1963-72.

19. Nakamura M, Nakamura S, Oku T. Suppressive response of confections containing the extractive from leaves of Morus Alba on postprandial blood glucose and insulin in healthy human subjects. Nutr Metab (Lond). 2009;6:29.

20. Czyżewska-Majchrzak $Ł$, Grzelak T, Kramkowska M, Czyżewska K, Witmanowski H. The use of lowcarbohydrate diet in type 2 diabetes-benefits and risks. Ann Agric Environ Med. 2014;21(2):320-6.

21. Dyson P. Low carbohydrate diets and type 2 diabetes: What is the latest evidence? Diabetes Ther. 2015;6(4):411-24.

22. Redondo-Cuenca A, Villanueva-Suarez MJ, Mateos-Apricio I. Soybean seeds and its by-product okara as sources of dietary fibre. Measurement by AOAC and englyst methods. Food Chem. 2008;108(3):1099-105.

23. Singh A, Meena M, Kumar D, Dubey AK, Hassan MI.Structure and functional analysis of various globulin proteins from soy seed. Crit Rev Food Sci Nutr. 2015; 55(11):1491-502.

24. Mateos-Aparicio I, Redondo-Cuenca A, Villanueva-Suarez ML, Zapate-Revilla MA, Tenorio-Sanz MD. Pea pod, broad bean pod and okara, potential sources of functional compounds. LWT Food Sci Technol. 2010;43:1467-70.

25. Rinaldi VEA, Ng PKW, Bennink MR. Effects of extrusion on dietary fiber and isoflavones contents of wheat extrudates enriched with wet okara. Cereal Chem. 2000;77(2):237-40.

26. Vital ACP, Croge C, Silva DF, Araújo PJ, Gallina MZ, Matumoto-Pintro PT. Okara residue as source of antioxidants against lipid oxidation in milk enriched with omega- 3 and bioavailability of bioactive compounds after in vitro gastrointestinal digestion. J Food Sci Technol. 2018;55(4):1518-24.

27. Suruga K, Akiyama Y, Kadokura K, Sekino Y, Kawagoe M, Komatsu Y, et al. Synergistic effect on reactive oxygen scavenging activity of fermented okara and banana by XYZ system. Food Sci 
Technol Res. 2007;13(2):139-44.

28. Suruga K, Kato A, Kadokura K, Hiruma W, Sekino Y, Buffinton CAT, et al. "Okara" a new preparation of food material with antioxidant activity and dietary fiber from soybean. In: El-Shemy $\mathrm{H}$, editor. Soybean and Nutrition. London: IntechOpen; 2011.p.311-26.

29. Wang K, Wu K, Xiao M, Kuang Y, Corke H, Ni X, et al. Structure characterization and properties of konjac glucomannan and zein blend film. Int J Biol Macromol. 2017;105:1096-104.

30. Zhao Y, Jayachandran M, Xu B. In vivo antioxidant ad anti-inflammatory effects of soluble dietary fiber konjac glucomannan in type-2 diabetic rats. Int J Biol Macromal. 2020;159(15):1186-96.

\section{Figures}

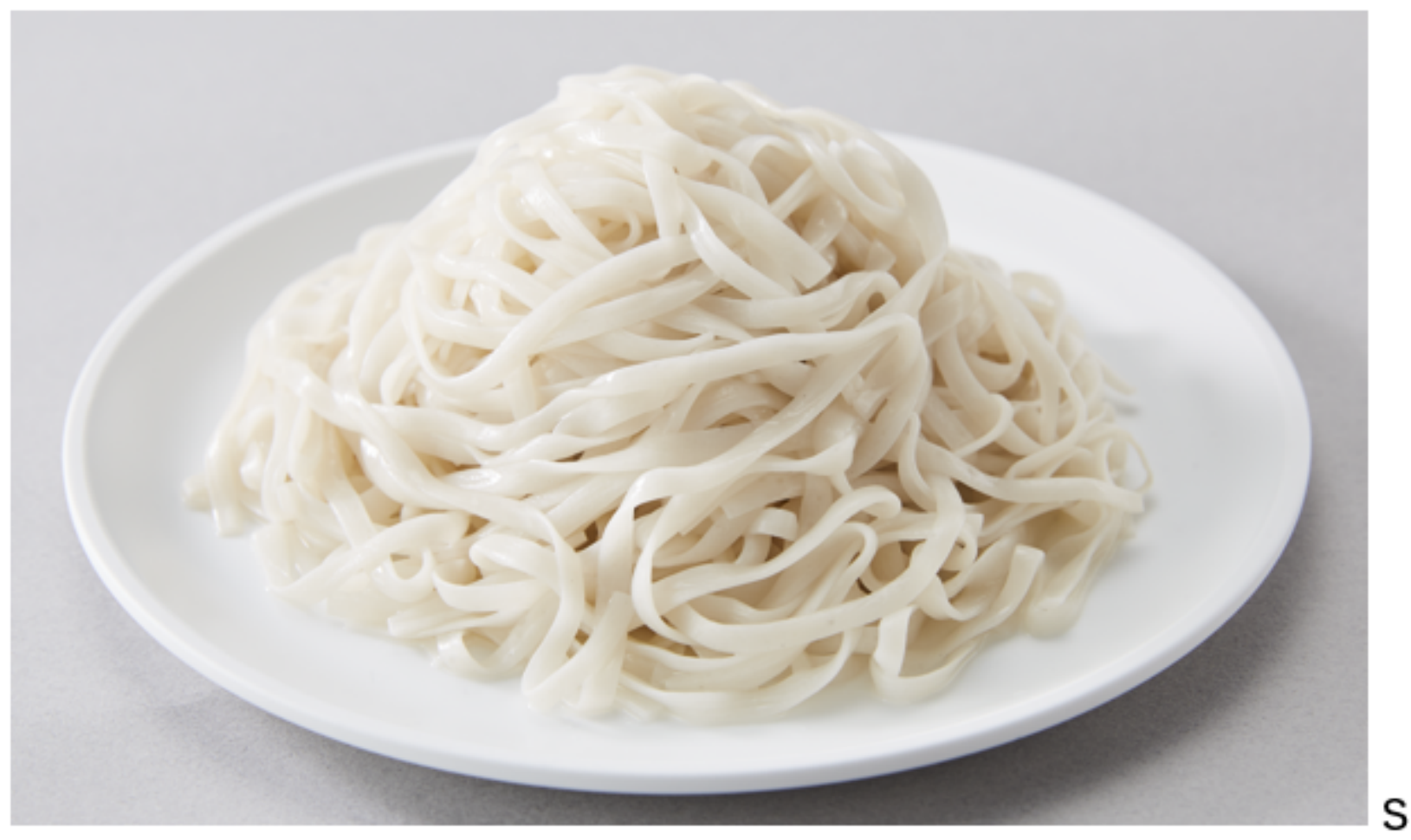

\section{Figure 1}

Low-sugar and high-dietary fiber noodles, Kibun Healthy NoodleTM. 


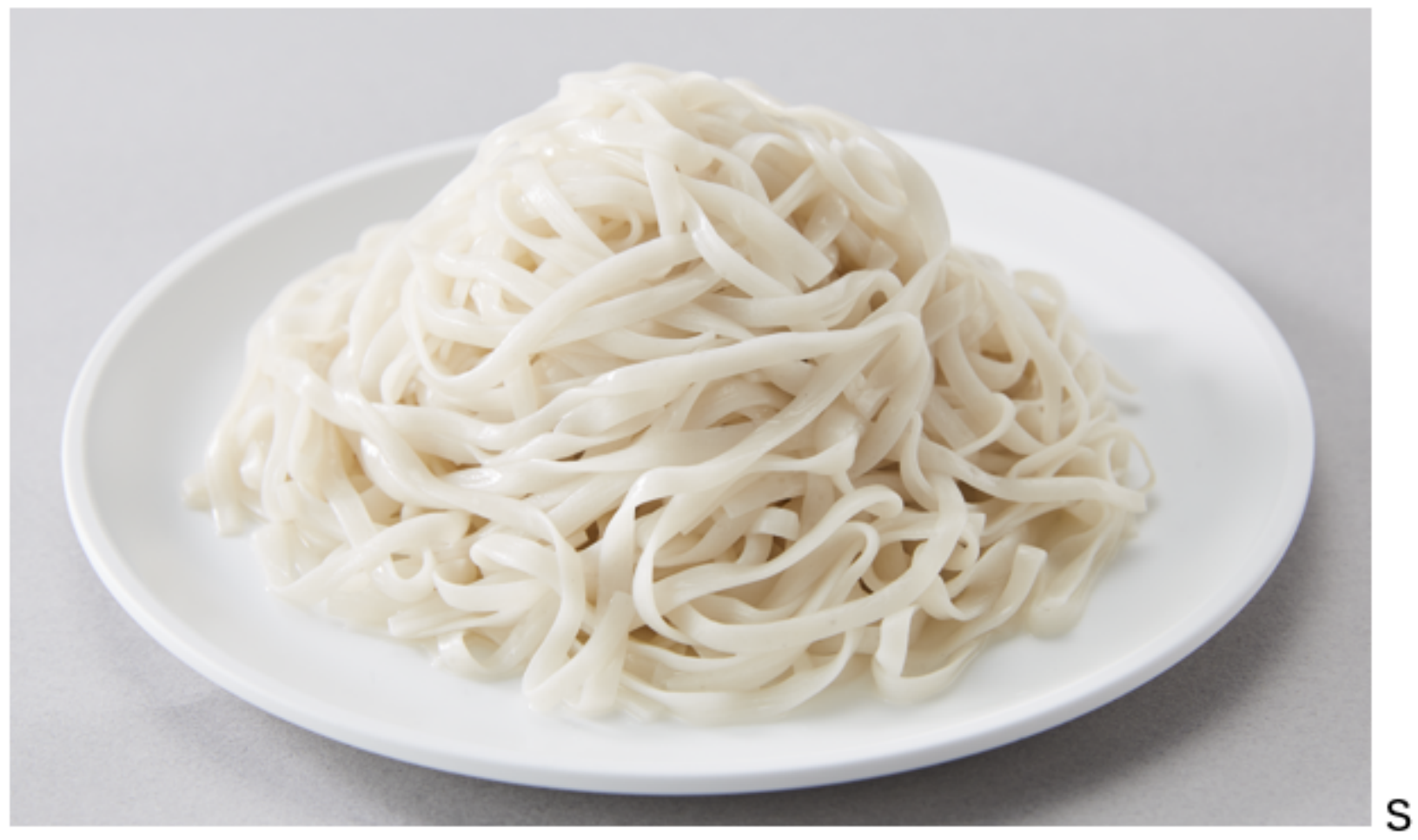

Figure 1

Low-sugar and high-dietary fiber noodles, Kibun Healthy NoodleTM.

(A)

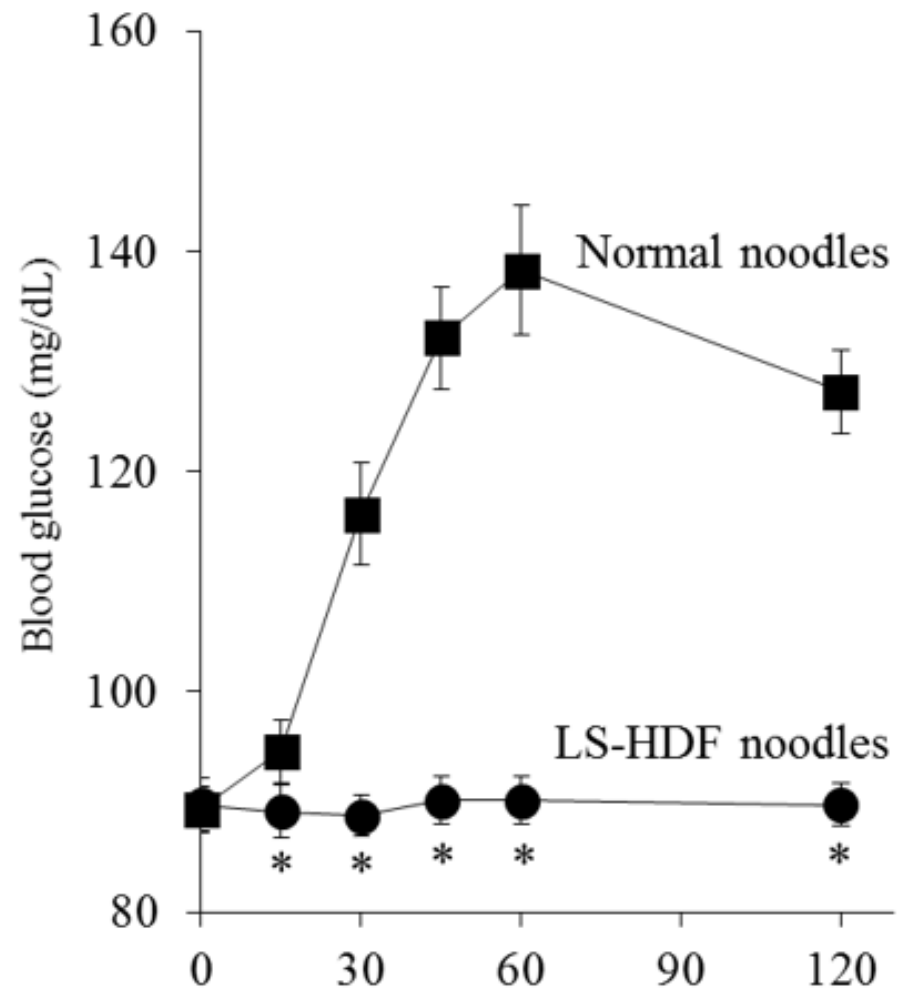

Time interval after oral administration (min)
(B)

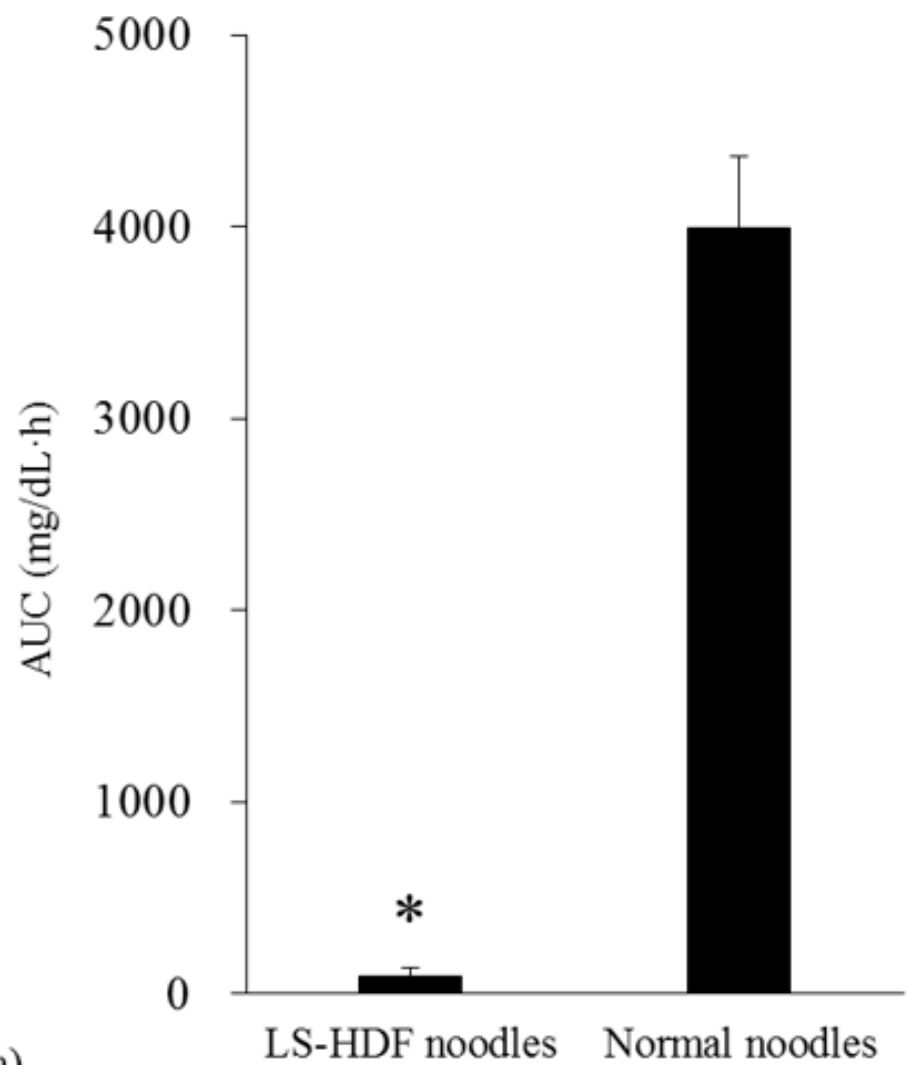


Figure 2

Change in plasma glucose level (A) and area under the glucose concentration-time curve (B) in healthy humans. Results are expressed as mean \pm standard error $(n=6)$. ${ }^{*} p<0.01 \mathrm{vs.} \mathrm{normal} \mathrm{noodles} \mathrm{group.}$

(A)

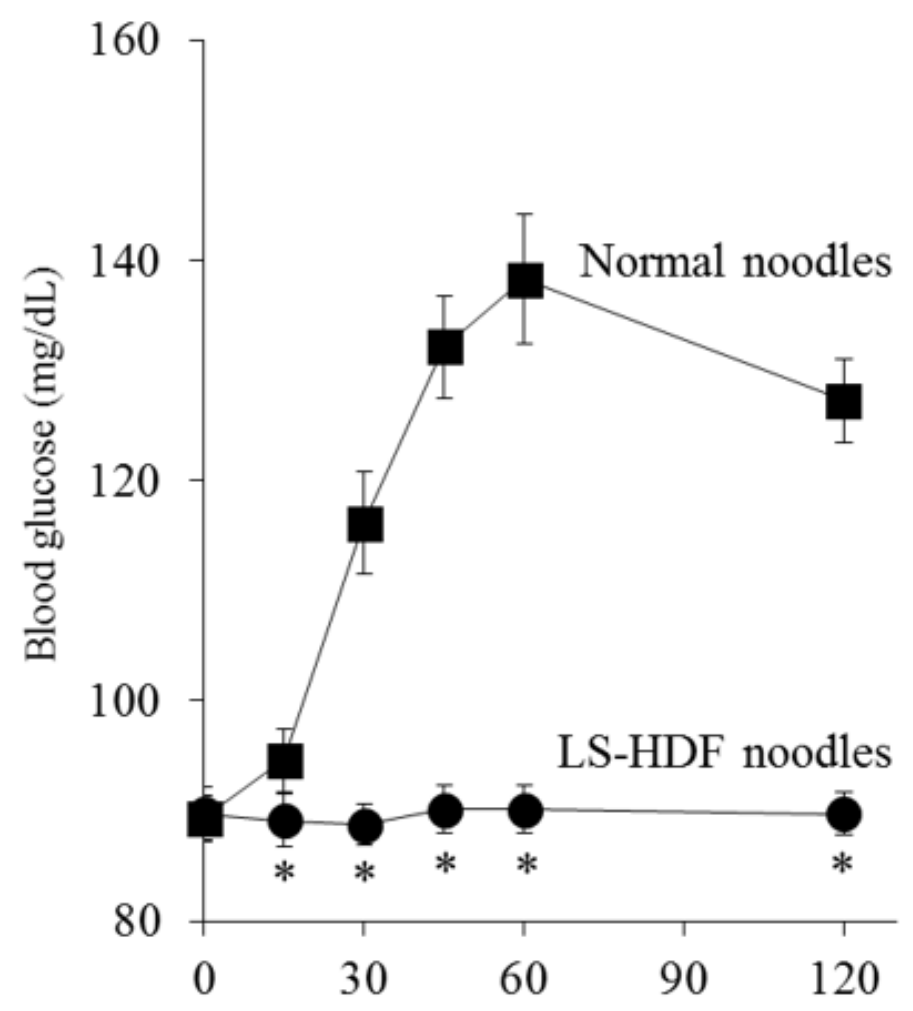

Time interval after oral administration (min)
(B)

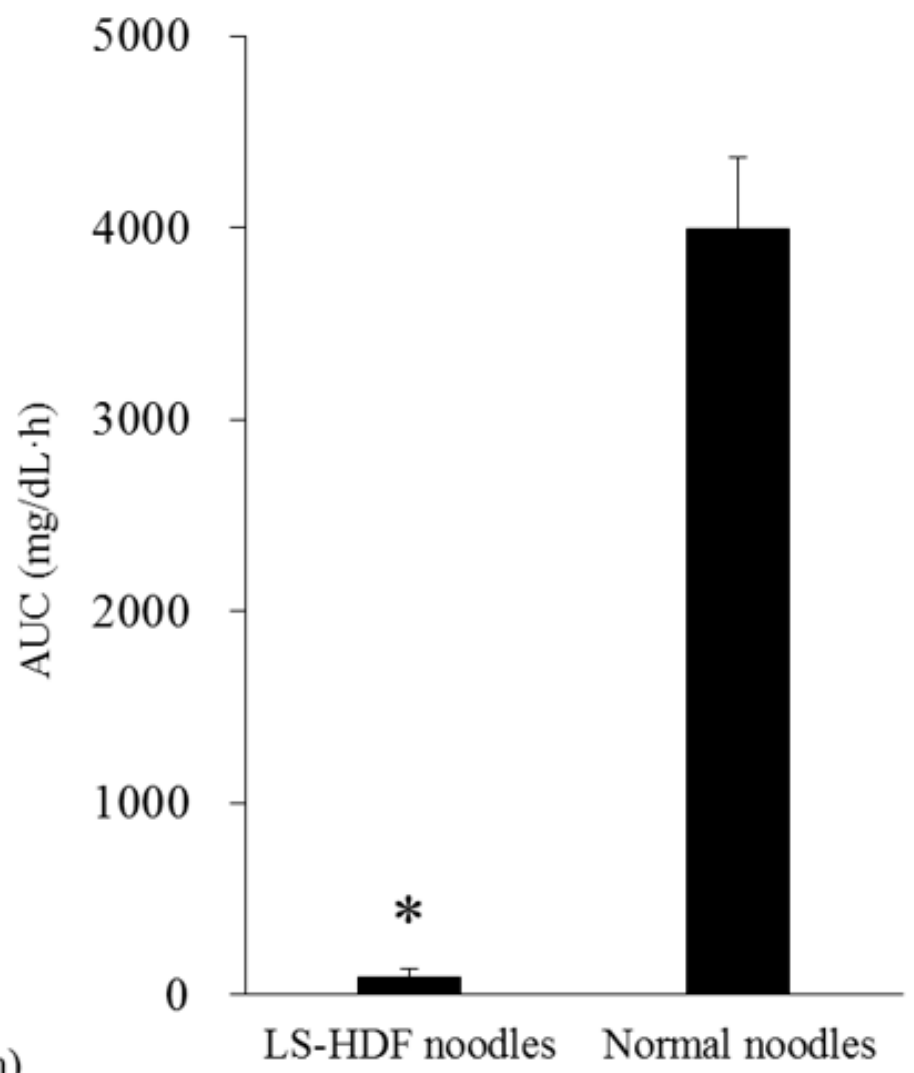

\section{Figure 2}

Change in plasma glucose level $(A)$ and area under the glucose concentration-time curve (B) in healthy humans. Results are expressed as mean \pm standard error $(n=6)$. ${ }^{\star} p<0.01$ vs. normal noodles group. 
(A)

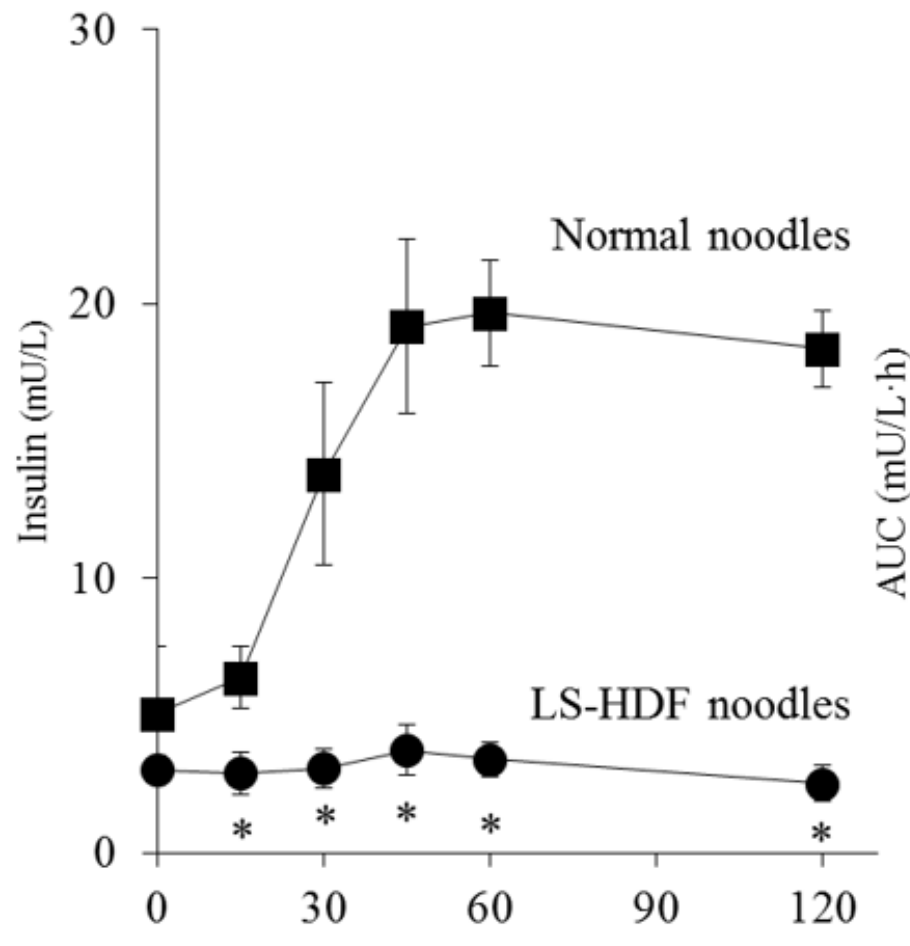

Time interval after oral administration (min)
(B)

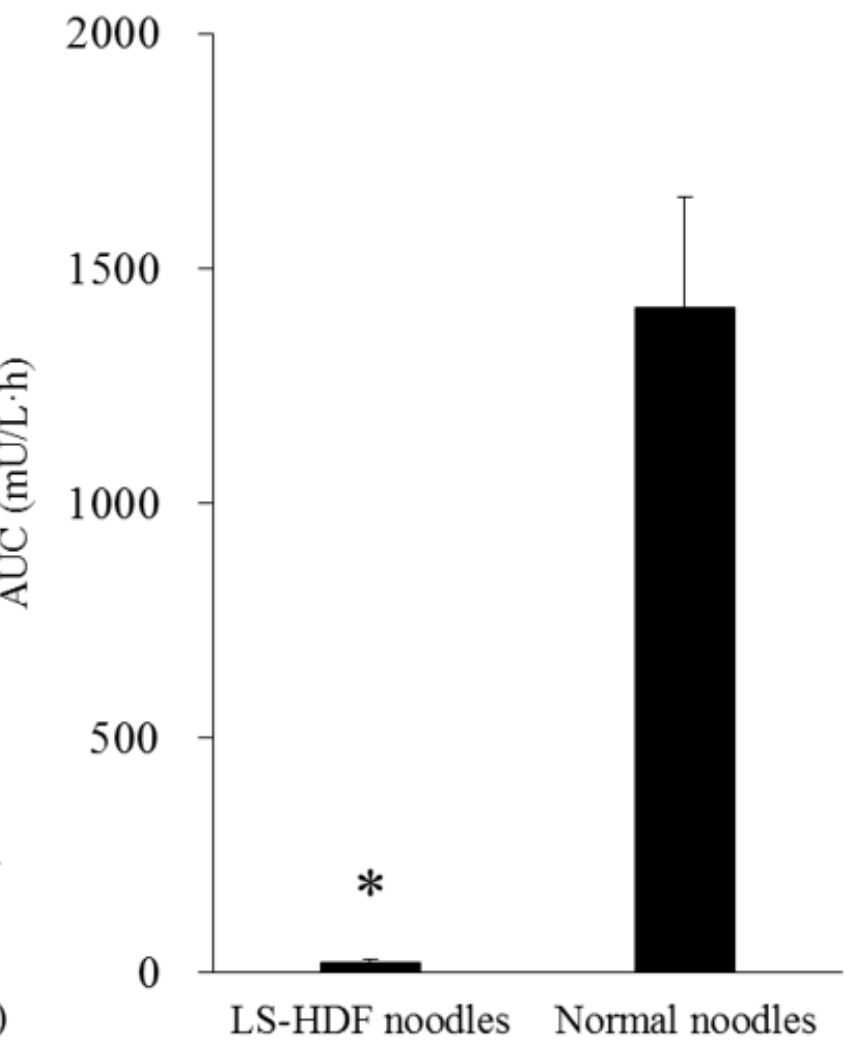

\section{Figure 3}

Change in insulin level (A) and area under the insulin concentration-time curve (B) in healthy humans. Results are expressed as mean \pm standard error $(n=6)$. ${ }^{*} p<0.01$ vs. normal noodles group. 
(A)

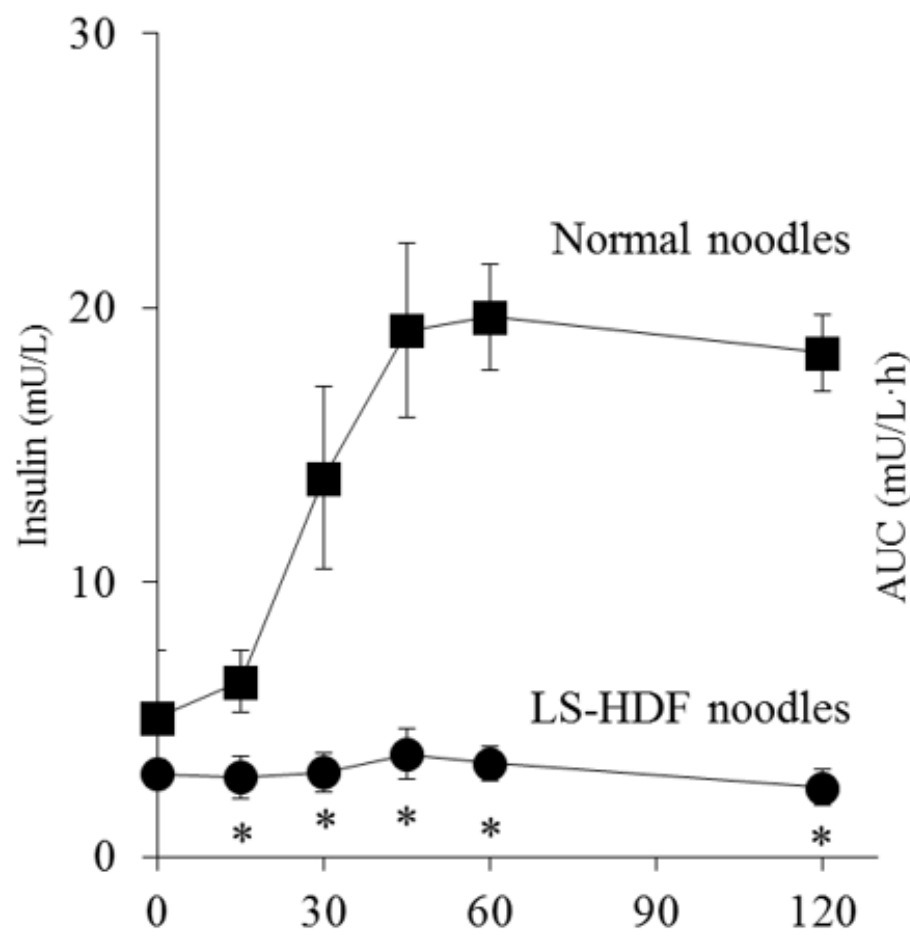

Time interval after oral administration (min)
(B)

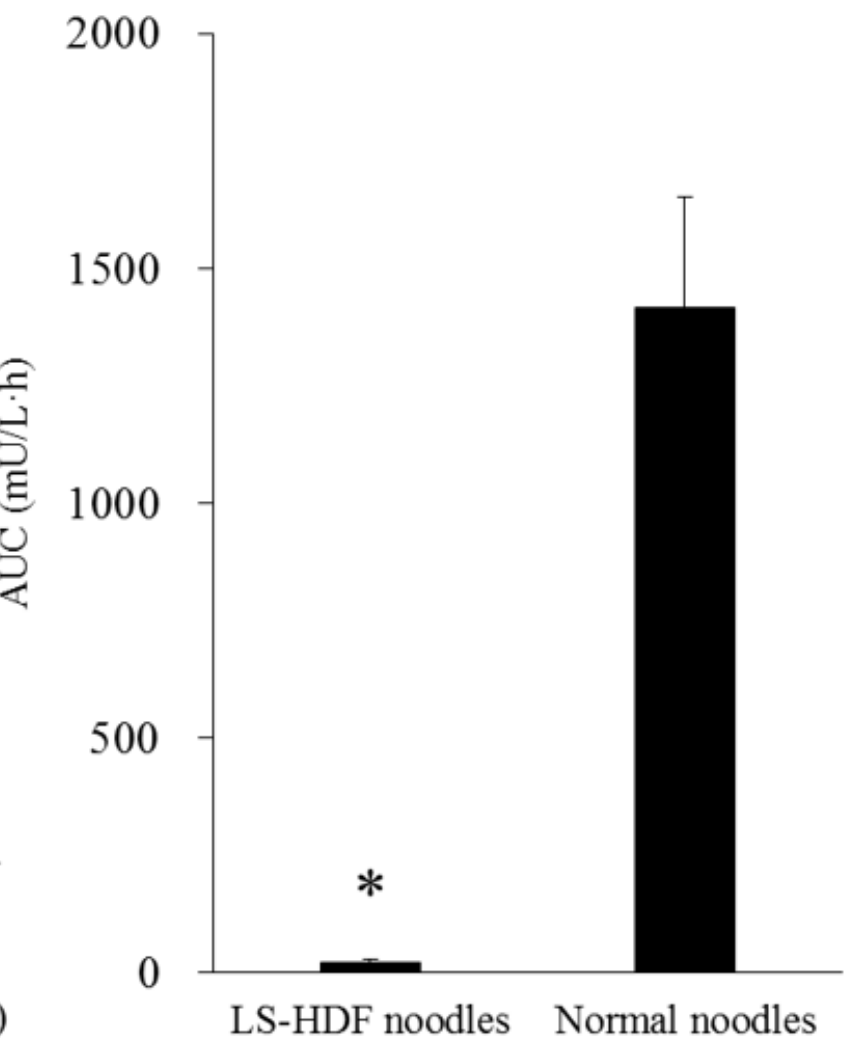

\section{Figure 3}

Change in insulin level (A) and area under the insulin concentration-time curve (B) in healthy humans. Results are expressed as mean \pm standard error $(n=6)$. ${ }^{*} p<0.01$ vs. normal noodles group. 